\title{
KNOWLEDGE, ATTITUDE \& PRACTICES TOWARDS ORGAN DONATIONAMONGST DENTAL \& MEDICAL STUDENTS \& PROFESSIONALS IN \& AROUND MELMARUVATHUR
}

\section{Prithivi Sankar Nanthakumar., Gokkulakrishnan Sadhasivam., Karthikeyan M., Suresh Kumar G., Abishek. R. Balaji and Srinivasulu P.,}

\author{
Department of Oral \& Maxillofacial Surgery, Adhiparasakthi Dental College \& Hospital, \\ Melmaruvathur, The Tamilnadu Dr. M. G. R. Medical University
}

DOI: http://dx.doi.org/10.24327/ijrsr.2017.0805.0289

\section{ARTICLE INFO}

\section{Article History:}

Received $18^{\text {th }}$ February, 2017

Received in revised form $10^{\text {th }}$

March, 2017

Accepted $06^{\text {th }}$ April, 2017

Published online $28^{\text {th }}$ May, 2017

\section{Key Words:}

Organ donation, Students, Healthcare, Awareness, Knowledge

\begin{abstract}
Transplantation is defined as the transfer (engraftment) of human cells, tissues or organs from a donor to recipient with an aim of restoring function(s) in the body. But in almost every country the number of willing organ donors falls short of the number of people on the waiting list by many thousands. As health care personnel we remain one of the most reliable sources for general population to get information about a relatively safe procedure. This study aims to determine the knowledge, attitude and practices towards organ donation amongst the Students \& Staff members of Adhiparasakthi Dental College \& Hospital, Melmaruvathur \& Melmaruvathur Adhiparasakthi Institute of Medical Sciences \& Research, Melmaruvathur and the variation amongst the study population and determination of the factors that cause the variation. The most significant factors which contributed to a positive attitude about organ donation were age, stream of study, father's occupation, family's monthly income, mother's education level.
\end{abstract}

Copyright (C) Prithivi Sankar Nanthakumar et al, 2017, this is an open-access article distributed under the terms of the Creative Commons Attribution License, which permits unrestricted use, distribution and reproduction in any medium, provided the original work is properly cited.

\section{INTRODUCTION}

Transplantation is defined as the transfer (engraftment) of human cells, tissues or organs from a donor to recipient with an aim of restoring function(s) in the body (1). On December $23^{\text {rd }}$, 1954, the first organ transplantation was carried out in the history of surgery and it is one of the most important findings in the field of transplantation(2). A kidney was transplanted between two identical twin brothers Richard \& Ronald Herrick by Dr. Joseph Hume at Brighton, Birmingham for which the operating surgeon received the noble prize. Since then we have come a long way to reach our present state. But in almost every country the number of willing organ donors falls short of the number of people on the waiting list by many thousands (3). Asian countries in particular have significant disparity between the number of waiting organ recipients and willing organ donors (4). The main reason for this disparity is the nonwillingness of individuals for organ donation(5). Many factors must be taken into account when studying the knowledge and attitudes of people towards organ donation. A variety of factors influence these attitudes towards organ donation and these factors vary greatly with geographic location, education level and other factors. As health care personnel we remain one of the most reliable sources for general population to get information about a relatively safe procedure. But, before we impart knowledge, we ourselves must be thoroughly informed about organ donation. Basic information on procedures, pros and cons and the ethical issues involving organ donation should be included in the dental and medical undergraduate curriculum, so that future doctors can become informed advocates(6).

\section{Aims of this Study}

This study aims to determine the knowledge, attitude and practices towards organ donation amongst the Students \& Staff members of Adhiparasakthi Dental College \& Hospital, Melmaruvathur \& Melmaruvathur Adhiparasakthi Institute of Medical Sciences \& Research, Melmaruvathur and the variation amongst the study population and determination of the factors that cause the variation.

\section{MATERIALS AND METHODS}

A cross sectional questionnaire based study was conducted amongst the students and staff members of Adhiparasakthi 
Dental College \& Hospital, Melmaruvathur \& Melmaruvathur Adhiparasakthi Institute of Medical Sciences, Melmaruvathur. The study sample comprised of undergraduate \& postgraduate dental students and the staff members from the dental college. From the medical college, samples were collected from the undergraduate students and the staff members. Anonymity and confidentiality of respondents were maintained and participation was voluntary. A 39 item self-administered questionnaire was developed based on previous studies $(2,5,7-$ 10). The questionnaire comprised of four sections. The first section of the questionnaire gathered the demographic details from the students, which included age, gender, year of study, religion and parents education level. The remaining three sections consisted of questions to judge the knowledge, attitude and practices of the individuals towards organ donation. Some questions were based on the dichotomous scale whereas other questions were based on a four point likert scale. After obtaining permission from the higher authorities the questionnaires were distributed to the students during lecture classes. The participants were instructed not to discuss with one another to avoid the possibility of a bias or a confounding factor. Only questionnaires which were fully completed were included in the study. Once the questionnaires were completed the data was compiled into a Microsoft Excel spreadsheet and the Statistical Analysis was carried out using IBM SPSS for Microsoft Windows version 23. Correlation between knowledge, attitude and practice scores was calculated by Pearson's correlation coefficient. A $p$ value $<0.05$ was considered statistically significant.

\section{RESULTS}

A total of 750 questionnaires were handed out to the undergraduate students, postgraduate students and the staff members of Adhiparasakthi Dental College \& Hospital and Melmaruvathur Adhiparasakthi Institute of Medical Sciences. 619 questionnaires were collected back after completion. The response rate was $82.53 \%$. The remaining questionnaires were either incomplete or the individuals were not willing to participate in the study due to varied reasons.

Out of the 619 participants $68.49 \%$ belonged to Adhiparasakthi Dental College \& Hospital $(n=424)$ and 31. 51 $\%$ belonged to Melmaruvathur Adhiparasakthi Institute of Medical Sciences $(\mathrm{n}=195)$. In Adhiparasakthi Dental College \& Hospital 86 participants belonged to the first year, 94 belonged to the second year, 84 belonged to the third year, 99 belonged to the fourth year and 61 were from the Compulsory Rotary Internship. In Melmaruvathur Adhiparasakthi Dental College \& Hospital, 133 belonged to the first year, 55 belonged to the final year and 7 were from the Compulsory Rotary Internship. The study population comprised of $31.3 \%$ of males $(n=194)$ and $68.7 \%$ of females $(n=425)$. The mean age was 19.3 years with a standard deviation of \pm 2.1 years. Out of the 619 individuals, $18.9 \%$ were 17 years of age $(n=117), 29.4$ $\%$ were 18 years of age $(n=182), 9 \%$ were 19 years of age $(9.0 \%), 12.6 \%$ were 20 years of age $(n=78), 16.3 \%$ were 21 years of age $(n=101), 9.9 \%$ were 22 years of age $(n=61)$, 2. $6 \%$ were 23 years of age $(n=16)$ and $1.4 \%$ were 24 years of age and above $(n=8)$.

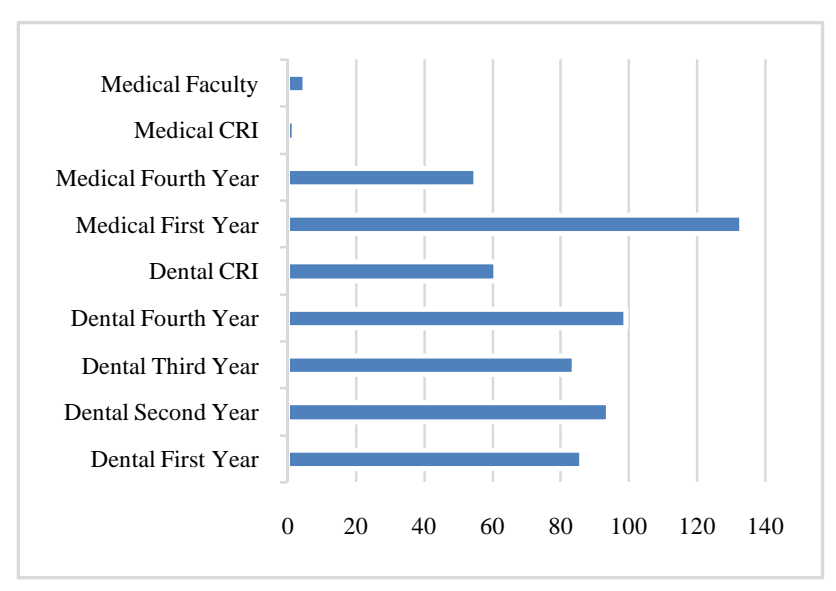

As religious beliefs can influence an individual's perception towards organ donation the distribution of various religions was analyzed. 91. $6 \%$ of the individuals from the study population were Hindu $(\mathrm{n}=573), 2.7 \%$ of the individuals were Christian $(\mathrm{n}=17), 4.2 \%$ of the individuals were Muslim $(\mathrm{n}=26)$ and $0.5 \%$ of the individuals were Jain $(\mathrm{n}=3)$.

Amongst the study population $1.6 \%$ of the participants had a mother whose line of work was Healthcare $(n=10)$ and $1.9 \%$ participants had a father who was into Healthcare as a line of work $(n=16) .32 .8 \%$ individuals of the study population came from a family whose cumulative income was less than 25,000 rupees $(n=203), 34.6 \%$ individuals came from a family whose cumulative income was in between 25,000 rupees to 50,000 rupees $(n=214), 23.4 \%$ individuals came from a family whose cumulative income was in between 50,000 rupees to $1,00,000$ rupees $(n=145)$ and $9.2 \%$ individuals came from a family whose monthly income was more than $1,00,000$ rupees $(n=57)$.

When the mother's level of education was analyzed it was found that $5.3 \%$ had completed primary school education $(\mathrm{n}=$ $33), 6.1 \%$ had completed till secondary level of education $(\mathrm{n}=$ $38), 19.2 \%$ had completed high education $(n=119), 14.7 \%$ had completed higher secondary education $(\mathrm{n}=91)$ and 54.6 $\%$ had completed their college education.

When the father's level of education was recorded and looked into it was found that $3.7 \%$ had completed primary school education $(\mathrm{n}=23), 5.5 \%$ had completed secondary school education $(\mathrm{n}=34), 12 \%$ had completed their high school education $(\mathrm{n}=74), 14.4 \%$ had completed their higher secondary education $(\mathrm{n}=89)$ and $64.5 \%$ had completed their college education $(n=399)$.

19. $8 \%$ of the participant's family strongly agreed with the concept of organ donation $(\mathrm{n}=118), 55.1 \%$ of the participant's family somewhat agreed with the concept of organ donation $(n=341), 15.3 \%$ somewhat disagreed with the concept of organ donation $(n=95)$ and $10.5 \%$ of the participant's family strongly disagreed with the concept of organ donation $(n=65)$.

$56.2 \%$ of the participant's strongly agreed with the concept of organ donation $(n=348), 36.7 \%$ of the participants somewhat agreed with the concept of organ donation $(n=227), 4.8 \%$ somewhat disagreed with the concept of organ donation $(\mathrm{n}=$ 
30) and $2.3 \%$ of the participants strongly disagreed with the concept of organ donation $(n=14)$.

6. $5 \%$ of the study population were registered organ donors ( $\mathrm{n}$ $=40$ ) and $93.5 \%$ of the study population were not registered organ donors $(n=579) .9 .7 \%$ of the study population had family members who were registered organ donors $(n=60)$, 73. $5 \%$ of the study population had no registered organ donors in the family $(\mathrm{n}=455)$ and $16.8 \%$ of the study population did not know whether they had a registered organ donor in the family $(\mathrm{n}=104)$.

49. $1 \%$ of the participants quoted the television as their first source of knowledge about organ donation $(n=304), 5.5 \%$ of the participants reported that the internet was their source of knowledge $(n=34), 2.4 \%$ of the participants got their information about organ donation from pamphlets and brochures $(n=15), 8.1 \%$ of the participants got their information from magazines $(\mathrm{n}=50), 1.8 \%$ of the participants got their knowledge from friends \& relatives $(n=11), 5.3 \%$ of the study population reported that their source of knowledge was from the hospital $(n=33)$ and $27.8 \%$ had more than one source of information $(n=172)$.

12. $8 \%$ of the population strongly agreed when asked whether most people who get an organ transplantation make a complete recovery $(\mathrm{n}=79), 58.5 \%$ of the population somewhat agreed $(\mathrm{n}=362), 26.8 \%$ of the study population somewhat disagreed $(\mathrm{n}=166)$ and $1.9 \%$ of the study population strongly disagreed to the aforementioned statement $(\mathrm{n}=12)$.

89. $2 \%$ of the study population were familiar with the term brain death $(n=552)$ and $10.8 \%$ of the study population were not familiar with the term brain death $(n=67)$.

12. $3 \%$ of the study population strongly believed that it is possible for a brain dead person to recover $(n=76), 18.3 \%$ of the study population somewhat agreed to the belief that it is possible for a brain dead person to recover $(n=113), 16.0 \%$ of the study population somewhat disagreed to the belief $(\mathrm{n}=$ 99) and $53.5 \%$ of the study population strongly disagreed to the statement $(\mathrm{n}=331)$.

A question was posed as to whether the individuals believed that if they indicated that they were an organ donor would the doctors be less likely to save their life. $11.8 \%$ of the study population strongly agreed to the statement $(n=73), 24.7 \%$ of the population somewhat agreed to the statement $(n=153), 23$. $9 \%$ of the study population somewhat disagreed to the statement $(\mathrm{n}=148)$ and $39.6 \%$ strongly disagreed to the statement $(\mathrm{n}=245)$.

When asked whether the waiting list for the organ transplantation was unbiased, $16.8 \%$ of the study population strongly agreed $(n=104), 33.9 \%$ of the study population somewhat agreed $(n=210), 24.9 \%$ of the study population somewhat disagreed $(n=154)$ and $24.4 \%$ of the study population strongly disagreed $(\mathrm{n}=151)$.

3. $1 \%$ had already registered with an organ donor foundation $(\mathrm{n}=19)$ and $96.9 \%$ of the study population had not registered with an organ donor registry $(n=600)$.

When the concept of supporting organ donation was compared amongst the medical and dental college students it was discovered that more number of medical undergraduate students strongly agreed with the concept of organ donation ( $\mathrm{p}$ value $=0.046$ ). It was analyzed and found that there was not much significance when the willingness of organ donation was compared between the sexes. The family's monthly income greatly influenced the attitudes of the persons included in the study. It was discovered that persons who were in the monthly income group of Rs. 50,000 - Rs. 1,00,000 were most willing for organ donation compared to individuals who came from the other groups $(\mathrm{p}$ value $=0.032$ ). There was no significance when the knowledge of the individual regarding organ donation and whether or not the individuals in the study had a parent in the health care field was cross tabulated. The most common and significant source of information regarding organ donation was the television $(p$ value $=0.029)$. As the age of the individual increased the willingness to the concept of organ donation increased. When religion and the willingness to donate organs were cross tabulated it was discovered that Christians were most willing to donate organs compared to people of other faiths ( $\mathrm{p}$ value $=0.022$ ). The medical fraternity had more number of registered organ donors compared to the dental students and staff members. The third years and the final years had the most in depth knowledge about the procedures involved in organ donation compared to the other years.

To conclude the most significant factors which contributed to a positive attitude about organ donation were:
1. Age
2. Stream of Study
3. Father's Occupation
4. Family's Monthly Income
5. Mother's Education Level

\section{DISCUSSION}

Organ donation can prove to be a life-saving treatment modality for people who have been diagnosed with an end stage organ disease but in most of the countries there is a wide disparity between the number of willing organ donors and the number of waiting recipients. This disparity may be attributed to a misconception towards the organ donation procedure. The willingness to donate one's organs may be greatly influenced by a variety of factors such as ethical beliefs, religious trends and information from a variety of sources. As healthcare professionals, we remain one of the most important sources of knowledge for the general public regarding organ donation. Hence, we must thoroughly be informed about organ donation before we can pass on the information to other individuals.

A plethora of studies have been published regarding the knowledge, attitude and practices of healthcare professionals regarding organ donation $(3,8,9,11-16)$. According to the study by Coad et $\mathrm{al}$, on young adults in the UK, $95 \%$ of participants were aware of "organ donation" and "organ transplantation" and the results for this particular question were similar in our study (17). In our study we also compared other variables which may affect the attitude towards organ donation such as gender, year of study and religion. In our study, males were more willing towards organ donation compared to females which contradicts with the studies by Burra et al (18) and Mekahli et al (19) on European medical students where females had higher positive attitude. 
The main limitation of our study was that the samples were taken from one geographical area and hence we have not studied the variation of attitudes amongst individuals from different geographical areas. Hence our study cannot be generalized to the population.

Increased awareness of organ donation and awareness about organ donor registries will help us curb the disparity between the organ donor and the organ recipients. More studies which include a vaster population from different geographical areas are required.

\section{CONCLUSION}

The knowledge, attitudes and practices of the medical and dental students towards organ donation can be greatly improved by increasing the knowledge amongst the students. Education about organ donation is the first step whereas the other steps which must be taken are education about various government and private organizations for organ donation.

If these steps are implemented the disparity between the donors and the recipients may be curbed.

\section{References}

1. WHO. Global Glossary of Terms and Definitions on Donation and Transplantation [Internet]. WHO. 2009. Available from: http:// www. who.int/ transplantation/ activities/en/

2. Bedi KK, Hakeem AR, Dave R, Lewington A, Sanfey H, Ahmad N. Survey of the Knowledge, Perception, and Attitude of Medical Students at the University of Leeds Toward Organ Donation and Transplantation. Transplant Proc [Internet]. 2015;47(2):247-60. Available from: http://www.sciencedirect.com/science/article/pii/S00411 34515000196

3. Majeed F. Saudi Nursing and Medical Student's Knowledge and Attitude toward Organ Donation- A Comparative Cross-Sectional study. Int J Health Sci (Qassim). 2016;10(2):210-7.

4. Tam WWS, Suen LKP, Chan HYL. Knowledge, Attitudes and Commitment Toward Organ Donation Among Nursing Students in Hong Kong. Transplant Proc [Internet]. 2012;44(5):1196-200. Available from: http://www.sciencedirect.com/science/article/pii/S00411 34512001534

5. Mikla M, Rios A, Lopez-Navas A, Gotlib J, Kilanska D, Martinez-Alarcón L, et al. Factors Affecting Attitude Toward Organ Donation Among Nursing Students in Warsaw, Poland. Transplant Proc [Internet]. 2015;47(9):2590-2. Available from: http://www.science direct.com/science/article/pii/S0041134515008957

6. Lima CX, Lima MVB, Cerqueira RG, Cerqueira TG, Ramos TS, Nascimento M, et al. Organ donation: crosssectional survey of knowledge and personal views of Brazilian medical students and physicians. Transplant Proc. 2010 Jun;42(5):1466-71.

7. Dardavessis T, Xenophontos P, Haidich A-B, Kiritsi M, Vayionas MA. Knowledge, Attitudes and Proposals of Medical Students Concerning Transplantations in Greece. Vol. 2, International Journal of Preventive Medicine. India; 2011. p. 164-9.
8. Bilgel H, Sadikoglu G, Bilgel N, Foun- A. Knowledge and Attitudes about Organ Donation Among Medical Students. Transplantationmedizin. 2006;18 (Supplement): 91-6.

9. Cantwell M, Clifford C. English nursing and medical students' attitudes towards organ donation. J Adv Nurs. 2000 Oct;32(4):961-8.

10. U.S. Department of Health \& Human Services. National Survey Organ Donation Attitudes and Behaviors. 2013.

11. Yuen CC, Burton W, Chiraseveenuprapund P, Elmore E, Wong S, Ozuah $\mathrm{P}$, et al. Attitudes and beliefs about organ donation among different racial groups. Vol. 90, Journal of the National Medical Association. 1998. p. $13-8$.

12. Chakradhar K, Doshi D, Srikanth Reddy B, Kulkarni S, Padma Reddy M, Sruthi Reddy S. Knowledge, Attitude and Practice Regarding Organ Donation among Indian Dental Students. Vol. 7, International Journal of Organ Transplantation Medicine. Shiraz, Iran; 2016. p. 28-35.

13. Hill EM. Posthumous organ donation attitudes, intentions to donate, and organ donor status: Examining the role of the big five personality dimensions and altruism. Pers Individ Dif [Internet]. 2016;88:182-6. Available from: http://www.sciencedirect.com/ science/article/pii/S0191886915005942

14. Kocaay AF, Celik SU, Eker T, Oksuz NE, Akyol C, Tuzuner A. Brain Death and Organ Donation: Knowledge, Awareness, and Attitudes of Medical, Law, Divinity, Nursing, and Communication Students. Transplant Proc [Internet]. 2015;47(5):1244-8. Available from: http://www.sciencedirect.com/ science/article/pii/ S0041134515003966

15. Petersen SR. Done vida-donate life: a surgeon's perspective of organ donation. Am J Surg [Internet]. 2007;194(6):701-8. Available from: http://www.science direct.com/science/article/pii/S0002961007007209

16. Oluyombo R, Fawale BM, Busari OA, Ogunmola JO, Olanrewaju TO, Akinleye CA, et al. Organ Donation Among Tiers of Health Workers. Transplant Direct [Internet]. 2016;2(1):e52. Available from: http:// content.wkhealth.com/linkback/openurl?sid=WKPTLP:1 andingpage\&an=01845228-201601000-00007

17. Chung CKY, Ng CWK, Li JYC, Sum KCY, Man AHY, Chan SPC, et al. Attitudes, knowledge, and actions with regard to organ donation among Hong Kong medical students. Hong Kong Med $J$ = Xianggang yi xue za zhi. 2008 Aug;14(4):278-85.

18. Burra P, De Bona M, Canova D, D'Aloiso MC, Germani G, Rumiati R, et al. Changing attitude to organ donation and transplantation in university students during the years of medical school in Italy. Transplant Proc. 2005 Mar;37(2):547-50.

19. Mekahli D, Liutkus A, Fargue S, Ranchin B, Cochat P. Survey of first-year medical students to assess their knowledge and attitudes toward organ transplantation and donation. Transplant Proc. 2009 Mar;41(2):634-8. 